\title{
Sexual and Reproductive Health and Rights of Women: A Rights-based Approach
}

\author{
Shaorin Tanira ${ }^{1}$, Raihana Amin ${ }^{2}$, Sanchita Adhikary ${ }^{3}$, Khadiza Sultana ${ }^{4}$, Rashida Khatun ${ }^{5}$ \\ 1. Graduate student, School of Rehabilitation Therapy, Faculty of Health Sciences, Queen's University, Kingston, \\ ON, Canada. Email: shaorin.tanira@queensu.ca (corresponding author) \\ 2. Junior Consultant (Gynaecology), Geriatric Hospital, Bangladesh Association for the Aged and Institute of \\ Geriatric Medicine (BAAIGM), Agargaon, Dhaka-1207, Bangladesh. Email: raihanaamin205@gmail.com \\ 3. Junior Consultant (Obstetrics \& Gynaecology), Jessore Sadar Hospital, Jessore-7400, Bangladesh. Email: \\ drsadhikary@gmail.com \\ 4. Medical Coordinator, Bangladesh Women's Health Coalition (BWHC), Adabor, Dhaka-1207, Bangladesh. \\ Email: chhonda17@gmail.com \\ 5. Graduate student, Department of Population Sciences, University of Dhaka, Dhaka-1000, Bangladesh. Email: \\ rashidakhatun6135@gmail.com
}

DOI: https://doi.org/10.3329/bioethics.v10i2.50667

\begin{abstract}
Violations of women's sexual and reproductive health and rights are frequent all over the world. Women's sexual and reproductive health is related to multiple human rights. The term 'rights-based' has become increasingly linked to the concept of a more comprehensive approach to sexual and reproductive rights of women around the globe. The rights-based perspective is derived from the treaties, pacts and other international commitments that recognize and reinforce human rights, including the sexual and reproductive rights of women. We conducted an extensive review of the guidelines, frameworks, research reports and published articles that have been cited as informing the rights-based approach. The findings of the review highlights what is meant by sexual and reproductive health and rights by the stakeholders, why this matter is important, and what can be done. It demands more partnerships with human rights, women's and other civil society organizations, increased number of successful national policies, initiatives and/or legislative changes, increased budget and other resources at national and/or local community level, mass communication and engagement of men to promote and advance women's sexual and reproductive health and rights. Achievement of gender equality is very crucial, because it is a human right that advances women's empowerment; and is interlinked with sexual and reproductive health and rights.
\end{abstract}

Key words: Sexual and reproductive health and rights, gender equality, women empowerment, women's rights.

Introduction: Access to comprehensive sexual and reproductive health and rights is a basic human right. However, violations of women's sexual and reproductive health rights are frequent all over the world ${ }^{1}$. The International Conference on Population and
Development (ICPD) Programme of Action recognizes that realizing the right to reproductive health is a critical element of guaranteeing reproductive rights ${ }^{1}$. The ICPD Programme of Action broadly defines reproductive health as "a state of complete 
physical, mental and social well-being and not merely the absence of disease or infirmity, in all matters relating to the reproductive system and to its functions and processes"2. Moreover, according to the ICPD Programme of Action, sexual and reproductive rights "rest on the recognition of the basic right of all couples and individuals to decide freely and responsibly the number, spacing and timing of their children and to have the information and means to do so, and the right to attain the highest standard of sexual and reproductive health" ${ }^{2}$ and also include the right "to make decisions concerning sexuality and reproduction free of discrimination, coercion and violence, as expressed in human rights documents" 2 . The rights-based perspective is derived from the "treaties, pacts and other international commitments that recognize and reinforce human rights"3, including the sexual and reproductive rights of women. This paper is the outcome of an extensive review of the guidelines, frameworks, research reports and published articles that have been cited as informing the rights-based approach to women's sexual and reproductive health and rights.

\section{Current situation and challenges: Maternal} mortality, gender-based violence, lack of access to appropriate health care and an absence of family planning services drive violations of reproductive rights across the world ${ }^{4}$. An estimated 287,000 maternal deaths occurred worldwide in 2010; most of them were preventable. However, the aggregate data masks gross inequalities both within and between countries. For instance, the risk of dying during pregnancy, and when giving birth, for a woman in a developing region is 15 times higher than in developed regions. In total, $99 \%$ of maternal deaths occur in the developing world, mainly in Africa and South Asia ${ }^{5}$. In addition, more than 200 million women annually are estimated to experience life-threatening complications in connection with pregnancy, often leading to serious disability ${ }^{6} .3$ million babies die in the first week of life and even more are stillborn every year ${ }^{7}$. The main reason behind the large number of preventable maternal and infant mortality, underpinning the disparities between and within the world's regions, is a lack of quality health care ${ }^{8}$. Despite an increased focus on voluntary family planning, among other interventions, there are still large gaps in the availability of contraceptive services, especially in sub-Saharan Africa and other developing countries where unmet need is near about $25 \%$, while the global average is around $11 \% 9$. It has been estimated that more than 120 million women have unmet needs for family planning services ${ }^{9}$. Those women hardly decide freely on whether to have children and the number and timing of child bearing, and are more vulnerable to contracting sexually transmitted infections (STIs), including HIV/AIDS ${ }^{4,8}$. Lack of access to family planning services also increases the rate of abortions, including unsafe abortions - an estimated yearly 80 million unwanted or unintended pregnancies each year and an estimated 45 million are terminated. Of those, 19 million are unsafe with almost $40 \%$ done on women below 25 years of age. About 68,000 women die each year from complications of unsafe abortion ${ }^{6}$. Lack of formal education (especially primary 
and secondary) for girls not only reflects insufficient access to health education (especially sexual health and family planning), but also illustrates the behind the scene facts: a world in which adolescent girls are forced or otherwise coerced into sex and/or marriage $e^{4,9}$. Child, early and forced marriages (and early unions without marriage) are among the many harmful practices affecting young girls, primarily in the developing world ${ }^{9}$. These violations of reproductive rights - childbirth before physical and mental readiness - a common consequence of early marriages, can lead to obstetric fistula and other detrimental health consequences for both babies and mothers. Additionally, evidence shows that adolescent mothers are much less likely to have access to formal and health education than adolescent girls not affected by motherhood $^{11}$. Moreover, patriarchal concepts of women's roles within the family mean that women are often valued based on their ability to reproduce ${ }^{10}$. Women are also often blamed for infertility. Besides, early marriage and pregnancy, or repeated pregnancies spaced too closely together, often as the result of efforts to produce male offspring because of the preference for sons, has a devastating impact on women's health with sometimes fatal consequences ${ }^{9-11}$. Therefore, international community has acknowledged that maternal mortality and other associated vulnerabilities are primarily a human rights challenge and a social justice issue $^{12}$.

Rights-based approach: The term 'rightsbased' has become increasingly linked to the concept of a more comprehensive approach to sexual and reproductive rights of women around the globe. Reproductive rights are a constellation of freedoms and entitlements that are already recognized in national laws, international human rights instruments and other consensus documents. Reproductive rights refer to a diversity of civil, political, economic, social and cultural rights affecting the sexual and reproductive life of individuals and couples ${ }^{2}$. The Universal Declaration of Human Rights (UDHR) is a milestone document in the history of human rights. Drafted by representatives with different legal and cultural backgrounds from all regions of the world, the Declaration was proclaimed by the United Nations General Assembly in 1948, as a common standard of achievements for all peoples and all nations ${ }^{13}$. It has been further shaped by major United Nations conferences of the 1990s that focused on human rights, gender equality, sexual and reproductive health, and HIV and AIDS, as well as by the most important document, the 1994 International Conference on Population and Development (ICPD), which was adopted by consensus and later endorsed by the United Nations General Assembly $^{2}$. Another important document, also adopted by consensus and endorsed by the United Nations General Assembly, is the Beijing Declaration and Platform for Action, adopted in 1995 at the Fourth World Conference on Women ${ }^{14}$. Furthermore, the 2005 World Summit Outcome, adopted by the United Nations General Assembly in $2005,{ }^{15}$ and the commitment to both sexual and reproductive health in the outcome document of the 2010 United Nations Summit on the Millennium Development Goals, adopted by the United Nations 
General Assembly in 2010, ${ }^{16}$ further confirmed the commitment to reproductive health. In June 2012, the United Nations reaffirmed its commitment to reproductive rights in the United Nations Conference on Sustainable Development, Rio+20. ${ }^{17}$

Women's sexual and reproductive health is related to multiple human rights, including the right to life, the right to be free from torture, the right to health, the right to privacy, the right to education, and the prohibition of discrimination ${ }^{1,10,18}$. Achievement of gender equality is very crucial, because it is a human right; advances women's empowerment; and is interlinked with sexual and reproductive health and rights ${ }^{19,20}$. Effectively addressing reproductive health problems calls for an integrated, rights-based approach that draws on the fields of health, ethics, law and human rights. This approach can provide analytical tools to identify root causes and inequities, shape humane and effective programmes and policies, and pressure governments into working proactively ${ }^{18}$.

Implementation mechanisms: While hardwon gains for sexual and reproductive health and rights often face backlash and set-backs, several organizations around the globe, together with UN Agencies, are determined and fighting to change the status quo ${ }^{19}$. Gender equality, the concept that all individuals should be treated in a way that ensures equal opportunities and outcomes, is a human right. The highest attainable standard of sexual and reproductive health is not possible without gender equality ${ }^{5}$ and this has been recognized at the level of international policy. For example, the Sustainable Development Goals (SDGs) recognize that sustainable development cannot be achieved without gender equality $^{21}$. Not only is gender equality a goal in itself i.e. goal 5, but there is a specific target within this goal on universal access to SRH (target 5.6), in addition to a target on $\mathrm{SRH}$ in the health goal (target 3.7) ${ }^{21}$. Hence, addressing gender inequality is a prerequisite for respecting, protecting and fulfilling the right to sexual and reproductive health. It demands more partnerships with human rights, women's and other civil society organizations, increased number of successful national policies, initiatives and/or legislative changes, increased budget and other resources at national and/or local community level, mass communication and engagement of men to promote and advance women's sexual and reproductive health and rights ${ }^{1}$.

The provision of reproductive health services must conform to the international human rights framework comprising the right to health such as the standards guaranteeing availability, accessibility, acceptability, and quality of health facilities, goods, and services $^{22}$. These are regarded as core components of the right to sexual and reproductive health.

a) Availability: States must ensure that there are an adequate number of functioning health care facilities, services, goods and programs to serve the population, including essential medicines such as contraception and emergency contraception.

b) Accessibility: States must ensure that health facilities and services are accessible 
both physical and economically to their populations without any discrimination. Information also must be accessible so that individuals and groups must be able to seek, receive, and disseminate information and ideas on health issues.

c) Acceptability: Health facilities, services, and goods must be culturally appropriate and should take into account the interests and needs of minorities, indigenous populations, and different genders and age groups.

d) Quality: Reproductive health care must be of good quality, meaning that it is scientifically and medically appropriate and that service providers receive adequate training.

To summarize the above discussions, we may say that through all those treaties, meetings and conferences, three points of focus forged a new consensus on reproductive rights ${ }^{16}-\mathrm{i}$ ) Individuals have the right to control their sexual and reproductive lives without interference, while governments must ensure equal access to health care, including comprehensive reproductive health services; ii) A rights-based approach can provide health practitioners with an ethical framework and understanding of societal factors. It can improve the effectiveness of interventions and empower clients; and iii) international human rights treaty obligations can increase pressure on governments, as well as raise the visibility of sexual and reproductive health problems.

Conclusion: All the above discussions can be summarized as violations of the major human rights concepts of liberty (incorporating autonomy), social justice, and equality around the globe, while we talk on sexual and reproductive health and rights of women. Moreover, the discourse of human rights cannot provide readymade answers to the problems and dilemmas that arise in any given context. However, where several measures present themselves as comparably effective, the preference should be for the alternative that is the least detrimental to the enjoyment of human rights. Struggles over women's rights to sexual and reproductive health have also been crucial in advancement of women's rights movement. For decades, women's rights advocates have drawn attention to the ways in which the status of women is fundamentally linked with their sexuality and reduction. This sort of approach means trusting women as autonomous beings who can actively exercise control over their sexual and reproductive lives and to make decisions on these matters on the basis of access to adequate information. To conclude, improvement of reproductive and sexual health and rights directly affects equitable and sustainable development, the attainment of various Millennium Development Goals (MDGs).

\section{References:}

1. United Nations Population Fund (UNFPA) Center for Reproductive Rights (CRR). ICPD and human rights: 20 years of advancing reproductive rights through UN treaty bodies and legal reform. 2017. Available from:

https://www.unfpa.org/sites/default/files/pubpdf/icpd_and_human_rights_20_years.pdf (Accessed August 27, 2017).

2. United Nations. Report of the International Conference on Population and Development (ICPD), Cairo, 1994. 1995. Available from: https://www.un.org/development/desa/pd/sites/w 
ww.un.org.development.desa.pd/files/icpd_en.pd f (Accessed June 29, 2017).

3. Berglas NF, Constantine NA, Ozer EJ. A rightsbased approach to sexuality education: conceptualization, clarification and challenges. Perspect Sex Reprod Health. 2014;46(2):63-72.

4. Temmerman M, Khosla R, Say L. Sexual and reproductive health and rights: a global development, health, and human rights priority. Lancet. 2014;384(9941):e30-1.

5. World Health Organization (WHO), World Bank, United Nations Population Fund \& United Nations Children's Fund (UNICEF). Trends in maternal mortality: 1990 to 2010: WHO, UNICEF, UNFPA and The World Bank estimates. Geneva: WHO; 2012.

6. Glasier A, Gülmezoglu AM, Schmid GP, Moreno CG, Van Look PF. Sexual and reproductive health: a matter of life and death. Lancet. 2006;368(9547):1595-607.

7. World Health Organization. World Health Organization fact sheet. Making pregnancy safer. Saudi Med J. 2004;25(8):1133-5.

8. Rosenfield A, Min CJ, Freedman LP. Making motherhood safe in developing countries. N Engl J Med. 2007;356(14):1395-7.

9. United Nations Population Fund (UNFPA). How universal is access to reproductive health? A review of the evidence. New York: UNFPA; 2010.

10. United Nations Population Fund (UNFPA). Sexual and reproductive health for all: Reducing poverty, advancing development and protecting human rights. New York: UNFPA; 2010.

11. United Nations Population Fund (UNFPA). Giving girls today and tomorrow, Breaking the cycle of adolescent pregnancy. New York: UNFPA; 2007.

12. United Nations Human Rights. Office of the High Commissioner. Reproductive rights are human rights: A handbook for national human rights institutions. 2014. Available from: https:/www.ohchr.org/documents/publications/n hrihandbook.pdf (Accessed June 17, 2017).

13. United Nations. Universal Declaration of Human Rights. Paris, 1948. 1948. Available from: https:/www.un.org/en/universal-declarationhuman-rights/ (Accessed June 18, 2017).

14. UN Women. Fourth World Conference on Women. Beijing, 1995. 1995. Available from: https://www.un.org/womenwatch/daw/beijing/pl atform/ (Accessed July 10, 2017).

15. United Nations. 2005 World Summit Outcome. 2005. Available from: https://www.un.org/en/development/desa/populat ion/migration/generalassembly/docs/globalcomp act/A_RES_60_1.pdf (Accessed July 11, 2017).

16. United Nations. United Nations Conference on Sustainable Development, Rio+20. Rio de Janeiro, 2012. 2012. Available from: https://sustainabledevelopment.un.org/rio20 (Accessed July 11, 2017).

17. United Nations. Millennium Development Goals Report, 2011. Available from: https://www.un.org/millenniumgoals/11_MDG\% 20Report_EN.pdf (Accessed July 17, 2017).

18. Kols A. A rights-based approach to reproductive health. UNFPA/Programme for Appropriate Technology in Health. New York: UNFPA; 2003.

19. Miller AM, Kismödi E, Cottingham J, Gruskin S. Sexual rights as human rights: a guide to authoritative sources and principles for applying human rights to sexuality and sexual health. Reprod Health Matters. 2015;23(46):16-30.

20. International Planned Parenthood Federation (IPPF). Gender Equality Strategy and Implementation Plan. 2010. Available from: https://www.ippf.org/sites/default/files/2018-

04/IPPF\%202017\%20Gender\%20Equality\%20St rategy\%20-\%20English.pdf (Accessed July 15, 2017).

21. United Nations. Open Working Group session on Promoting Equality, including Social Equity, Gender Equality and Women's Empowerment. Joint Statement to the Open Working Group on the Sustainable Development Goals (SDGs). 2014. Available from: http://sustainabledevelopment.un.org/content/doc uments/6405argentina.pdf (Accessed August 19, 2017).

22. Kumar J. How does quality of care relate to a rights-based approach to family planning programs? New York: Population Council; 2015. Available from: https:/www.popcouncil.org/uploads/pdfs/2015R H_QOC-RightsBasedFP_wp1.pdf (Accessed August 9, 2017).

Authors' contribution: S Tanira was involved in conception of the paper; S Tanira, R Amin, S Adhikary, K Sultana and $\mathrm{R}$ Khatun were equally involved in the literature search, manuscript writing and revision.

Conflict of interest: None to disclose. 